\title{
Effect of Vitamin D3 Supplementation on Insulin Sensitivity in Prediabetes With Hypovitaminosis D: A Randomized Placebo-Controlled Trial
}

\author{
Munibuddin M. Ahmed ${ }^{1}$, Urjita S. Zingade ${ }^{2}$, Khaled M. Badaam ${ }^{1}$ \\ 1. Physiology, Government Medical College, Aurangabad, IND 2. Physiology, Rajarshi Chhatrapati Shahu Maharaj \\ Government Medical College, Kolhapur, IND
}

Corresponding author: Munibuddin M. Ahmed, physiologist1@gmail.com

\section{Abstract \\ Introduction}

The interplay of vitamin D and glucose metabolism is an area of ongoing research. The need for vitamin D supplementation trials in individuals with prediabetes and hypovitaminosis D has been stressed by earlier research studies. The objective of this study was to assess the effect of vitamin D3 supplementation on oral glucose insulin sensitivity (OGIS) index in patients with prediabetes and hypovitaminosis D.

\section{Methods}

We enrolled 120 individuals with prediabetes (ADA definition) and hypovitaminosis D (vitamin D $<30$ $\mathrm{ng} / \mathrm{mL}$ ) and randomized them into the vitamin D supplementation (60,000 IU weekly) group and the placebo group. Primary outcome measure (i.e., 2-hour OGIS index) and secondary outcome measures (i.e., fasting and postprandial blood glucose, glycosylated hemoglobin, body mass index, and insulin sensitivity indices, i.e., quantitative insulin sensitivity check index [QUICKI] and homeostatic model assessment for insulin resistance [HOMA-IR]) were analyzed for change with the 12 weeks of intervention.

\section{Results}

A total of 52 subjects in the vitamin D group and 49 in the placebo group completed the study. Serum vitamin D levels ( $10.11 \pm 2.73$ to $52.2 \pm 13.14 \mathrm{ng} / \mathrm{mL} ; \mathrm{p}<0.0001)$ and OGIS index (376.4 \pm 39.7 to $391.7 \pm 40.7$ $\mathrm{mL} / \mathrm{min} / \mathrm{m}^{2} ; \mathrm{p}=0.011$ ) increased significantly on per-protocol analysis in the vitamin $\mathrm{D}$ group. There was no significant change observed in vitamin D levels and OGIS index in the placebo group. Between-group comparison showed a rise in OGIS index $\left(15.3 \pm 47.1 \mathrm{~mL} / \mathrm{min} / \mathrm{m}^{2}\right)$ in the vitamin D group and decrease in OGIS index $\left(-10.4 \pm 44.7 \mathrm{~mL} / \mathrm{min} / \mathrm{m}^{2}\right)$ in the placebo group, and the difference was statistically significant ( $\mathrm{p}$ $=0.0029$ ) . The inter-group comparison showed relative fall in fasting glucose levels in the vitamin $\mathrm{D}$ group, with no significant change observed in the other secondary outcome measures.

Review began $11 / 29 / 2020$ Review ended 12/04/2020 Published 12/10/2020

() Copyright 2020 Ahmed et al. This is an open access article distributed under the terms of the Creative Commons Attribution License CC-BY 4.0., which permits unrestricted use, distribution, and reproduction in any medium, provided the original author and source are credited.

\section{Conclusions}

The correction of hypovitaminosis D in subjects with prediabetes led to improved insulin sensitivity as assessed by OGIS index at 120 minutes, signifying the role of vitamin D in glucose homeostasis.

Categories: Endocrinology/Diabetes/Metabolism

Keywords: oral glucose insulin sensitivity (ogis) index, vitamin d deficiency, insulin resistance, glucose, type b insulin resistance, glucose metabolism, impaired glucose tolerance, 25 (oh) vitamin d, vitamin d

\section{Introduction}

A recent Indian Council of Medical Research-India diabetes (ICMR-INDIAB) study has estimated a population prevalence of prediabetes in India to be $24.7 \%$, i.e., almost a quarter of adult population belongs to a high-risk group that can progress to diabetes mellitus in the near future [1]. Also, the prevalence of hypovitaminosis D has reached epidemic proportions in spite of the abundant sunshine in the region [2]. Studies in animals and human cohort studies have found an association of vitamin D with insulin secretion and action. An inverse association of vitamin D levels with insulin resistance has been found by observational studies [3,4]. However, supplementation trials with vitamin D in subjects with deranged glucose metabolism have reported inconsistent results. There has been an interest in studying the impact of vitamin D supplementation on glycaemic indices in subjects with prediabetes and hypovitaminosis D. Oral glucose tolerance test (OGTT) based insulin sensitivity test, i.e., oral glucose insulin sensitivity (OGIS) index at 120 minutes, is a simple surrogate marker related to pathophysiology of diabetes that can be used for research studies in large subjects [5]. With this background, this study was undertaken to evaluate the effect of oral vitamin D3 supplementation on OGIS and glycemic status in the subjects with prediabetes and hypovitaminosis D. 


\section{Materials And Methods}

This parallel-group double-blind randomized placebo-controlled trial was conducted at Government Medical College in Marathwada region of Maharashtra. The hypothesis was that vitamin D3 supplementation improves OGIS index in prediabetes subjects with hypovitaminosis D. Sample size was calculated as 49 subjects per group for one-tailed hypothesis testing ( $\alpha$ error at $5 \%$ for $80 \%$ power of study) to compare the change in OGIS values between the groups. The mean OGIS index and anticipated improvement in OGIS from the available literature were used for the calculation [6,7]. Due to possible attrition, the sample size was increased to 60 in each group. Approval was obtained prior to data collection from the Institutional Ethics Committee. Informed written consent was obtained from all the participants in the language known to them. Trial registration was done with the Clinical Trial Registry of India (CTRI/2012/12/003221) and the World Health Organization registry network (URN: U1111-1134-6536). This trial was conducted in accordance with the principles of the Helsinki declaration.

\section{Participants and eligibility criteria}

Eligible participants were adults aged $>25$ years with prediabetes and hypovitaminosis D. Prediabetes was defined as per the American Diabetes Association (ADA) criteria, i.e., fasting plasma glucose of 100 to 125 $\mathrm{mg} / \mathrm{dL}$ or 2-hour glucose concentration of 140 to $199 \mathrm{mg} / \mathrm{dL}$ after 75 -g oral glucose, or glycosylated hemoglobin (HbA1c) of 5.7\% to 6.4\% [8]. Hypovitaminosis D was defined as serum $25(\mathrm{OH}) \mathrm{D}<30 \mathrm{ng} / \mathrm{mL}$ [9] as per the Institute of Medicine guidelines. All known cases of diabetes, prediabetes patients on pharmacotherapy, subjects using supplements that contained vitamin D, and known cases of hypercalcemia, hyperparathyroidism, nephrolithiasis, chronic kidney disease, or other major illness were excluded. Participants were recruited from the medical college, from private hospitals, and through medical camp and direct contacts.

\section{Outcome measures}

Primary outcome measure was OGIS index at 120 minutes. Secondary outcome measures were fasting blood glucose, post-prandial blood glucose, HbA1c, body mass index (BMI), and insulin sensitivity indices (quantitative insulin sensitivity check index [QUICKI] and homeostatic model assessment for insulin resistance [HOMA-IR]).

\section{Screening}

History taking, general examination, systemic examination, and necessary investigations were performed in the subjects willing to participate in the study. Height was measured by a portable stadiometer marked up to $200 \mathrm{~cm}$. Weight was measured by a portable weighing machine, with a maximum capacity of $180 \mathrm{~kg}$. BMI was calculated as weight in kilograms divided by the square of height in meters. Screening of 157 high-risk subjects was done by the physician based on ADA reports (having BMI $>25 \mathrm{~kg} / \mathrm{m}^{2}$, physical inactivity, first degree relative of a diabetic) [10,11]. All the subjects were investigated for 2-hour OGTT (0, 90, and 120 minutes), HbA1c, and vitamin D levels. A total of 37 subjects were excluded as 29 were normoglycemic and eight were having normal vitamin D levels. The enrolled 120 subjects were allotted serial numbers.

\section{Sample collection and its evaluation}

After an overnight 12-hour fast, under aseptic precautions, $4 \mathrm{~mL}$ of venous blood was collected in a syringe for the measurement of HbA1c, plasma glucose, serum insulin, and serum 25(OH)D. Two-hour OGTT with a solution containing 75-gm glucose was performed. Blood samples were again drawn after 90 and 120 minutes for plasma glucose and serum insulin measurement. Plasma glucose was measured at 0, 90, and 120 minutes, and the serum insulin was measured at 0 and 90 minutes. Plasma glucose $(\mathrm{mg} / \mathrm{dL})$ was estimated using the glucose oxidase peroxidase (GOD-POD) method [12]. Serum insulin ( $\mu \mathrm{U} / \mathrm{mL})$ and $25(\mathrm{OH}) \mathrm{D}(\mathrm{ng} / \mathrm{mL})$ were estimated by electrochemiluminescence immunoassay (ECLIA ${ }^{\circledR}$; Elecsys, Roche, Mannheim, Germany). HbA1c (\%) was measured using ion-exchange HPLC (D-10 ${ }^{\text {TM }}$, Bio-Rad, Hercules, CA, USA). OGIS index $\left(\mathrm{mL} / \mathrm{min} / \mathrm{m}^{2}\right)$ [13] was calculated from Excel spreadsheet available at http://webmet.pd.cnr.it/ogis/. QUICKI was evaluated by the following formula using the calculator available at https://sasl.unibas.ch/11calculatorsQUICKI.php: 1 / [(log (fasting insulin in $\mu \mathrm{U} / \mathrm{mL}$ ) + log (fasting glucose in mg/dL)] [14,15]. HOMA-IR was calculated according to the following formula using Excel spreadsheet available at https://www.dtu.ox.ac.uk/homacalculator/: fasting insulin $(\mu \mathrm{U} / \mathrm{L}) \mathrm{x}$ fasting glucose $(\mathrm{nmol} / \mathrm{L}) / 22.5$ [16].

\section{Randomization and intervention}

Eligible participants were randomly assigned in a 1:1 ratio to receive oral vitamin D soft gel (60,000 IU cholecalciferol) or matching placebo once a week (after breakfast) for 12 weeks. Randomization was performed using a computer-generated random-number sequence by the pharmacist. Allocation concealment was done by opaque containers. Participants were advised to maintain their usual diet and physical activity and to avoid taking any supplements containing vitamin D during the study. Compliance with consumption of medicine or placebo was assessed by phone follow-up and returning the container. Twelve weeks after supplementation, participants came to the center for their repeat testing of the outcome parameters. Out of the 120 subjects enrolled, 101 subjects reported for the post-intervention follow-up visit. 
The entire program was offered free of charge. The investigator, study, subjects, and statistician were blinded regarding the subject allocation.

\section{Statistical analysis}

The data were compiled and expressed as mean \pm SD. The statistical analysis was performed using Microsoft Excel and online calculators available at http://www.graphpad.com/quickcalcs and https://www.socscistatistics.com. A p-value of $<0.05$ was considered as statistically significant. All the variables were measured in both the groups before and after the supplementation of placebo or vitamin D. Final analysis was performed after 12 weeks of supplementation. All the variables were assessed according to per-protocol analysis $(n=52+49=101)$, whereas serum $25(\mathrm{OH}) \mathrm{D}$ and the primary objective, i.e., OGIS index, were also assessed as per intention-to-treat (ITT) analysis $(n=60+60=120)$ with the baseline observations carried forward (BOCF). Test for normality of data (Shapiro-Wilk test) was applied and based on that parametric (paired and unpaired t-test) or nonparametric tests (Wilcoxon signed-rank test and MannWhitney U test) were used for analysis.

\section{Results}

A total 101 subjects completed the study: 52 from the vitamin D group and 49 from the placebo group. Figure 1 shows the flow chart of the study progression. Mean age of the subjects was $41.1 \pm 8$ years in the vitamin D group and $41.6 \pm 7$ years in the placebo group (Table 1). After the intervention, on per-protocol analysis and within-group comparison, there was a significant improvement in vitamin D levels $(10.1 \pm 2.7$ to $52.2 \pm 13.1$ $\mathrm{ng} / \mathrm{mL} ; \mathrm{p}<0.001)$ in the vitamin D supplementation group, with no significant change in the placebo group. All the subjects in the vitamin D supplementation group attained vitamin D sufficiency. Insulin sensitivity as evaluated by OGIS index at 2 hours also increased significantly in the vitamin D supplementation group from $376.4 \pm 39.7$ to $391.7 \pm 40.7 \mathrm{~mL} / \mathrm{min} / \mathrm{m}^{2}$ ( $\mathrm{p}=0.011$ ), whereas there was a fall in the OGIS index in the placebo group, although the difference was not statistically significant (Table 2). On ITT analysis, similar results were observed on within-group comparison, with a significant rise in vitamin D levels and OGIS index in the vitamin D supplementation group (Table 3). Between-group comparison on per-protocol analysis showed an improvement in OGIS index $(+15.3 \pm 47.1)$ in the vitamin D group and decrease in OGIS index $(-10.4 \pm 44.7)$ in the placebo group, and difference was statistically significant $(p=0.0029)$. Between-group comparison with ITT analysis showed a statistically significant improvement in the OGIS index in the vitamin D supplementation group (Table 4). Secondary outcome measures were analyzed with per-protocol method, and there was a significant change observed only in fasting glucose (between-group comparison). No significant change was observed in BMI, HbA1c, fasting insulin levels, post-meal glucose and insulin levels, and insulin sensitivity index QUICKI and HOMA-IR between the groups (Table 5). 


\section{Cureus}

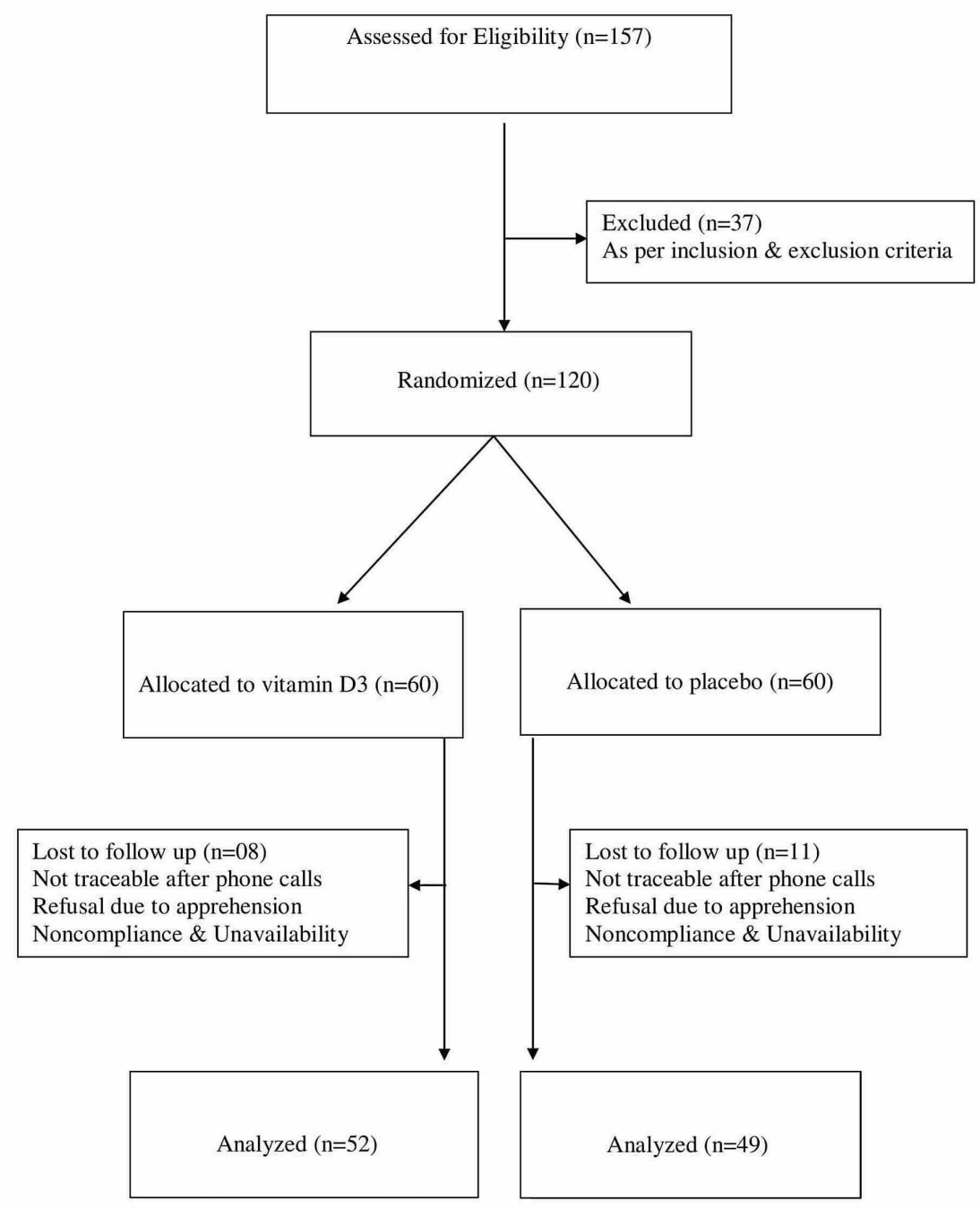

FIGURE 1: Flow chart of the study participants

\section{Variables}

\section{Age (years)}

Height (meters)

Weight (kg)

Body mass index $\left(\mathrm{kg} / \mathrm{m}^{2}\right)$
Vitamin D Group (Mean \pm SD)

( $n=52)$

$41.1 \pm 8$

$1.6 \pm 0.1$

$68.5 \pm 11.9$

$26 \pm 3.1$
Placebo Group (Mean \pm SD)

( $n=49)$

$41.6 \pm 7$

$1.6 \pm 0.1$

$70.7 \pm 10.7$

$26.3 \pm 2.7$

\section{TABLE 1: Baseline characteristics of the study subjects}




\section{Cureus}

\begin{tabular}{|c|c|c|c|c|c|c|c|c|}
\hline \multirow{2}{*}{ Variable } & \multicolumn{4}{|c|}{ Vitamin D Group (Mean \pm SD), $n=52$} & \multicolumn{4}{|c|}{ Placebo Group (Mean \pm SD), $n=49$} \\
\hline & $\begin{array}{l}\text { Pre-Vitamin D } \\
\text { Supplementation }\end{array}$ & $\begin{array}{l}\text { Post-Vitamin D } \\
\text { Supplementation }\end{array}$ & $\begin{array}{l}\text { Mean Difference } \\
{[95 \% \mathrm{Cl}]}\end{array}$ & $\mathrm{p}$-Value & $\begin{array}{l}\text { Pre- } \\
\text { Placebo }\end{array}$ & $\begin{array}{l}\text { Post- } \\
\text { Placebo }\end{array}$ & $\begin{array}{l}\text { Mean Difference } \\
{[95 \% \mathrm{Cl}]}\end{array}$ & $\begin{array}{l}\mathrm{p}- \\
\text { Value }\end{array}$ \\
\hline $\begin{array}{l}\text { Serum 25(OH)D } \\
\text { (ng/mL) }\end{array}$ & $10.1 \pm 2.7$ & $52.2 \pm 13.1$ & 42.1 [38.5 to 45.7$]$ & $<0.001^{*}$ & $\begin{array}{l}13.7 \pm \\
5.7\end{array}$ & $12.5 \pm 4.8$ & $-1.2[-3.1$ to 0.8$]$ & 0.153 \\
\hline $\begin{array}{l}\text { OGIS index } \\
\left(\mathrm{mL} / \mathrm{min} / \mathrm{m}^{2}\right)\end{array}$ & $376.4 \pm 39.7$ & $391.7 \pm 40.7$ & $15.3[2.5$ to 28.1$]$ & $0.011^{\star \star}$ & $\begin{array}{l}366.4 \pm \\
35.7\end{array}$ & $\begin{array}{l}355.9 \pm \\
30.1\end{array}$ & $-10.4[-22.9$ to 2.1$]$ & 0.054 \\
\hline
\end{tabular}

\section{TABLE 2: Per-protocol analysis of serum $25(\mathrm{OH}) \mathrm{D}$ and OGIS index}

*Highly significant; **Significant.

$\mathrm{SD}$, standard deviation; $\mathrm{CI}$, confidence interval; OGIS, oral glucose insulin sensitivity

\begin{tabular}{|c|c|c|c|c|c|c|c|c|}
\hline \multirow{2}{*}{ Variable } & \multicolumn{4}{|c|}{ Vitamin D Group (Mean \pm SD), $n=60$} & \multicolumn{4}{|c|}{ Placebo Group (Mean \pm SD), n = 60} \\
\hline & $\begin{array}{l}\text { Pre-Vitamin D } \\
\text { Supplementation }\end{array}$ & $\begin{array}{l}\text { Post-Vitamin D } \\
\text { Supplementation (BOCF) }\end{array}$ & $\begin{array}{l}\text { Mean Difference } \\
{[95 \% \mathrm{Cl}]}\end{array}$ & $\mathrm{p}$-Value & $\begin{array}{l}\text { Pre- } \\
\text { Placebo }\end{array}$ & $\begin{array}{l}\text { Post-Placebo } \\
\text { (BOCF) }\end{array}$ & $\begin{array}{l}\text { Mean Difference } \\
{[95 \% \mathrm{Cl}]}\end{array}$ & $\begin{array}{l}\mathrm{p} \text { - } \\
\text { Value }\end{array}$ \\
\hline $\begin{array}{l}\text { Serum 25(OH)D } \\
\text { (ng/mL) }\end{array}$ & $10.1 \pm 2.6$ & $46.6 \pm 19$ & 36.5 [31.7 to 41.3 ] & $<0.001^{*}$ & $\begin{array}{l}13.8 \pm \\
5.9\end{array}$ & $12.8 \pm 5.3$ & $-1[-2.6$ to 0.6$]$ & 0.307 \\
\hline $\begin{array}{l}\text { OGIS index } \\
\left(\mathrm{mL} / \mathrm{min} / \mathrm{m}^{2}\right)\end{array}$ & $376 \pm 39$ & $389.3 \pm 40.4$ & $13.3[2.1$ to 24.5$]$ & $0.011^{\star \star}$ & $\begin{array}{l}370.3 \pm \\
37\end{array}$ & $361.7 \pm 33.6$ & $\begin{array}{l}-8.5[-18.8 \text { to } \\
1.8]\end{array}$ & 0.054 \\
\hline
\end{tabular}

TABLE 3: Intention-to-treat analysis of serum 25(OH)D and OGIS index

*Highly significant; **Significant.

SD, standard deviation; $\mathrm{CI}$, confidence interval; BOCF, baseline observations carried forward; OGIS, oral glucose insulin sensitivity

\begin{tabular}{|c|c|c|c|c|c|c|}
\hline \multirow[b]{2}{*}{ Variable } & \multicolumn{3}{|l|}{ Per-Protocol Analysis } & \multicolumn{3}{|c|}{ Intention-to-Treat Analysis } \\
\hline & $\begin{array}{l}\text { Change in Vitamin D } \\
\text { Group (Mean } \pm \text { SD), } n= \\
52\end{array}$ & $\begin{array}{l}\text { Change in Placebo } \\
\text { Group (Mean } \pm \text { SD), } n \\
=49\end{array}$ & p-Value & $\begin{array}{l}\text { Change in Vitamin D } \\
\text { Group (Mean } \pm \text { SD), } n \\
=60\end{array}$ & $\begin{array}{l}\text { Change in Placebo } \\
\text { Group (Mean } \pm S D \text { ), } n \\
=60\end{array}$ & $p$-Value \\
\hline $\begin{array}{l}\text { Serum } \\
25(\mathrm{OH}) \mathrm{D} \\
\text { (ng/mL) }\end{array}$ & $42.1 \pm 13.2$ & $-1.2 \pm 7$ & $<0.001^{*}$ & $36.5 \pm 19$ & $-1 \pm 6.3$ & $<0.001^{*}$ \\
\hline $\begin{array}{l}\text { OGIS index } \\
\left(\mathrm{mL} / \mathrm{min} / \mathrm{m}^{2}\right)\end{array}$ & $15.3 \pm 47.1$ & $-10.4 \pm 44.7$ & $0.002^{\star \star}$ & $13.3 \pm 44.1$ & $-8.5 \pm 40.6$ & $0.002^{\star \star}$ \\
\hline
\end{tabular}

\section{TABLE 4: Comparison of change observed in serum 25(OH)D levels and OGIS index between} groups

*Highly significant; **Significant.

SD, standard deviation; OGIS, oral glucose insulin sensitivity 


\section{Cureus}

\begin{tabular}{|c|c|c|c|c|c|c|c|c|c|c|}
\hline \multicolumn{2}{|c|}{$\begin{array}{l}\text { Variables (Mean } \pm \\
\text { SD) }\end{array}$} & $\begin{array}{l}\text { Pre-Vitamin D } \\
\text { supplementation }\end{array}$ & $\begin{array}{l}\text { Post-Vitamin D } \\
\text { supplementation }\end{array}$ & $\begin{array}{l}\mathrm{p}- \\
\text { Value }\end{array}$ & $\begin{array}{l}\text { Pre-Placebo } \\
\text { Supplementation }\end{array}$ & $\begin{array}{l}\text { Post-Placebo } \\
\text { Supplementation }\end{array}$ & $\begin{array}{l}\mathrm{p}- \\
\text { Value }\end{array}$ & $\begin{array}{l}\text { Difference with Vitamin D } \\
\text { Supplementation }\end{array}$ & $\begin{array}{l}\text { Difference with Placebo } \\
\text { Supplementation }\end{array}$ & $\begin{array}{l}\text { p- } \\
\text { Value }\end{array}$ \\
\hline \multicolumn{2}{|c|}{$\begin{array}{l}\text { Body mass index } \\
\left(\mathrm{kg} / \mathrm{m}^{2}\right)\end{array}$} & $26 \pm 3.1$ & $26 \pm 3$ & 0.315 & $26.3 \pm 2.7$ & $26.2 \pm 2.8$ & 0.146 & $0.04 \pm 0.46$ & $-0.09 \pm 0.68$ & 0.121 \\
\hline \multicolumn{2}{|l|}{ HbA1c (\%) } & $5.8 \pm 0.4$ & $5.7 \pm 0.4$ & 0.146 & $5.8 \pm 0.4$ & $5.8 \pm 0.4$ & 0.206 & $-0.07 \pm 0.5$ & $0.05 \pm 0.3$ & 0.079 \\
\hline \multirow{3}{*}{$\begin{array}{l}\text { Glucose } \\
\text { (mg/dl) }\end{array}$} & min & $106.4 \pm 10.8$ & $103.6 \pm 11.7$ & 0.078 & $110.5 \pm 10.4$ & $114.2 \pm 9.2$ & 0.053 & $-2.8 \pm 14.2$ & $3.7 \pm 14.5$ & $0.018^{*}$ \\
\hline & $\begin{array}{l}90 \\
\text { min }\end{array}$ & $154.6 \pm 24.7$ & $156.7 \pm 21.2$ & 0.197 & $158.2 \pm 20.7$ & $160.8 \pm 17.6$ & 0.284 & $2.2 \pm 19$ & $2.7 \pm 27.4$ & 0.459 \\
\hline & min & $139.3 \pm 18.5$ & $137.5 \pm 17.5$ & 0.22 & $141.2 \pm 14.7$ & $144.6 \pm 13.9$ & 0.178 & $-1.7 \pm 15.9$ & $3.4 \pm 20.7$ & 0.083 \\
\hline \multirow{2}{*}{$\begin{array}{l}\text { Insulin } \\
(\mu \mathrm{U} / \mathrm{mL})\end{array}$} & $\begin{array}{l}0 \\
\min \end{array}$ & $7.8 \pm 3.6$ & $7.2 \pm 3$ & 0.197 & $6.9 \pm 3.6$ & $7 \pm 3.4$ & 0.452 & $-0.6 \pm 4.7$ & $0.1 \pm 2.6$ & 0.251 \\
\hline & min & $51.4 \pm 20$ & $46.5 \pm 20$ & 0.203 & $48.5 \pm 23.1$ & $47.7 \pm 17.4$ & 0.456 & $-4.9 \pm 28.6$ & $-0.9 \pm 26.9$ & 0.301 \\
\hline \multicolumn{2}{|l|}{ QUICKI } & $0.35 \pm 0.04$ & $0.35 \pm 0.02$ & 0.274 & $0.36 \pm 0.04$ & $0.35 \pm 0.03$ & 0.178 & $00 \pm 0.04$ & $-0.01 \pm 0.03$ & 0.079 \\
\hline \multicolumn{2}{|l|}{ HOMA-IR } & $2 \pm 1$ & $1.9 \pm 0.8$ & 0.125 & $1.9 \pm 1$ & $2 \pm 0.9$ & 0.211 & $-0.2 \pm 1.2$ & $0.1 \pm 0.7$ & 0.091 \\
\hline
\end{tabular}

TABLE 5: Comparison of secondary outcome variables before and after supplementation

*Statistically significant.

SD, standard deviation; HbA1c, glycosylated hemoglobin; QUICKI, quantitative insulin sensitivity check index; HOMA-IR homeostatic model assessment for insulin resistance

\section{Discussion}

All the study participants became vitamin D sufficient $(25(\mathrm{OH}) \mathrm{D}>30 \mathrm{ng} / \mathrm{mL})$ after supplementation with 60,000 IU of vitamin D3 soft gels weekly for 12 weeks. There was no significant change in vitamin D levels in the placebo group. There were no subjects with more than $100 \mathrm{ng} / \mathrm{mL}$ values of 25 -hydroxy vitamin $\mathrm{D}$ in our study group. Normalization of vitamin D levels with high-dose vitamin D supplements for a short period has been reported earlier [17].

The study results showed that there was an improvement in insulin sensitivity (OGIS index at 120 minutes) after correction of hypovitaminosis D. The improvement in OGIS index was around $4 \%$ in the vitamin D group, which is not large enough. Still, it was in contrast to a slight fall (3\%) in the OGIS index observed in the placebo group. The between-group comparison reflects a $7 \%$ statistically significant difference between the groups. Among the secondary outcome measures, fasting glucose showed improvement. In contrast, there was no significant change in HbA1c, BMI, post-prandial glucose levels, and insulin sensitivity measures based on fasting glucose and insulin values, i.e., HOMA-IR and QUICKI.

OGIS index included an overall assessment of insulin sensitivity and involved fasting and post-prandial status of glucose and insulin levels; therefore, change in either or both fasting and post-prandial insulin sensitivity impact the value of OGIS. Thus, even with moderate changes in HOMA-IR and QUICKI, which assess only the fasting status values of glucose and insulin, there can be a significant improvement in OGIS values. OGIS index has been reported to be a better surrogate marker of insulin sensitivity in comparison with other indices such as Matsuda index, QUICKI, and HOMA-IR, especially in subjects with prediabetes $[5,18]$.

The presence of vitamin D response element has been demonstrated on the human insulin receptor gene promoter, and 1,25 dihydroxy D3 has been shown to induce activation of the insulin receptor gene, potentiating the insulin response $[19,20]$. Insulin resistance in skeletal muscle mediated by forkhead box $\mathrm{O} 1$ (FOXO1), a critical negative regulator of insulin signaling, has been found to be linked to vitamin D [21]. Gröber and Holick reviewed the role of vitamin D in optimizing glucose metabolism and commented that vitamin D increases insulin sensitivity, thereby improving glucose tolerance [22]. A recent systematic review and meta-analysis by He et al. explored the vitamin D supplementation effect in nondiabetics. They found that fasting glucose levels were not changed by vitamin D supplementation in normoglycemic people and in individuals with normal vitamin D levels. Still, on subgroup analysis, they found that there was a fall in 
fasting glucose observed in subjects with prediabetes or low vitamin D. It was observed that in vitamin D deficient subjects ( $<20 \mathrm{ng} / \mathrm{mL}$ ), vitamin D repletion may prevent progression to diabetes [23]. The range of vitamin D deficiency spectrum in which there is a maximal response to correction of vitamin D deficiency is reported to be $16-36 \mathrm{ng} / \mathrm{mL}$. This range is speculated to have two to seven times more interaction of vitamin D3 with various metabolic parameters $[24,25]$. An improvement in the OGIS index by the supplementation of $50,000 \mathrm{IU}$ vitamin D per week for one year in the subjects with prediabetes and hypovitaminosis $\mathrm{D}$ has been reported [24]. In line with our results, a study from New Delhi, India, reported a significant improvement in OGIS in healthy nondiabetic but centrally obese men. The subjects with lower vitamin D levels and greater central adiposity benefited more from vitamin D supplementation concerning improvement in OGIS. No change in HOMA-IR, other fasting insulin sensitivity indices, and lipid profile was observed in the study [7]. A study from eastern India reported that progression to diabetes could be prevented in prediabetes subjects by repletion of low vitamin $\mathrm{D}$ levels. The results reflected a decrease in insulin resistance and inflammatory markers TNF-alpha (tumor necrosis factor-alpha) and IL-6 (interleukin-6) associated with it [26]. The improvement in insulin sensitivity/glycemic control by the correction of subnormal vitamin D in prediabetes subjects has been reported by various studies [27-29]. Contrary to our results, Davidson et al. demonstrated no benefit of attaining vitamin D sufficiency on the glucose homeostasis and insulin sensitivity in subjects with prediabetes. They used weekly high dose (mean: 88,865 IU) for one year [30].

The strengths of our study include recruiting prediabetes subjects who fall in a critical zone of suboptimal glucose metabolism spectrum. Also, the analysis of vitamin D levels at baseline and post-intervention was conducted. Furthermore, there was the attainment of vitamin D sufficiency in all subjects who completed vitamin $\mathrm{D}$ supplementation. The randomized placebo-controlled design and the study being done in a country which happens to be the diabetes capital of the world and has a high prevalence of hypovitaminosis $\mathrm{D}$ add to the significance of the study.

\section{Limitations}

There was no estimation of parathormone or serum calcium. The study was powered for OGIS index, and hence sample may not be sufficient to detect changes in other glycemic indices, and, for the same reason, a gender-based analysis was not conducted. Diet, sunlight exposure, physical activity, and other confounders affecting vitamin D metabolism were not taken into consideration; however, randomization may neutralize these limitations. Insulin area under the curve with multiple insulin measurement may better indicate insulin response as the values are dynamic.

\section{Conclusions}

To conclude, the study results and available literature reflect that the OGIS index may be improved in subjects of prediabetes with hypovitaminosis D by correcting the vitamin D levels. The role of vitamin D as a contributor in glucose regulation needs to be explored further to define its role in the management of deranged glucose metabolism. We recommend that subjects with prediabetes should be screened for vitamin D levels and that repletion should be done in subjects with hypovitaminosis D.

\section{Additional Information \\ Disclosures}

Human subjects: Consent was obtained by all participants in this study. Institutional Ethics Committee, GMC Aurangabad issued approval Pharma/IEC-GMCA/776/2011. Institutional Ethics Committee has unanimously approved your dissertation topic 'Effect of Vitamin D3 Supplementation on Insulin Sensitivity in Prediabetes with Hypovitaminosis D: A Randomized Placebo Controlled Trial' . Animal subjects: All authors have confirmed that this study did not involve animal subjects or tissue. Conflicts of interest: In compliance with the ICMJE uniform disclosure form, all authors declare the following: Payment/services info: All authors have declared that no financial support was received from any organization for the submitted work. Financial relationships: All authors have declared that they have no financial relationships at present or within the previous three years with any organizations that might have an interest in the submitted work. Other relationships: All authors have declared that there are no other relationships or activities that could appear to have influenced the submitted work.

\section{Acknowledgements}

We acknowledge the support provided by our college Dean, Dr. Kananbala A Yelikar, former Dean Dr. KS Bhople Professors in Physiology, Dr. Samina Khan, Dr. Syeda Afroz, and Dr. Nanda Somwanshi. We also acknowledge the support and efforts by the Physiology Department colleagues and the study team especially the volunteer subjects.

\section{References}

1. Anjana RM, Deepa M, Pradeepa R, et al.: ICMR-INDIAB Collaborative Study Group. Prevalence of diabetes and prediabetes in 15 states of India: results from the ICMR-INDIAB population-based cross-sectional study. Lancet Diabetes Endocrinol. 2017, 5:585-596. 10.1016/S2213-8587(17)30174-2

2. Ritu G, Gupta A: Vitamin D deficiency in India: prevalence, causalities and interventions . Nutrients. 2014, 
6:729-775. 10.3390/nu6020729

3. Chiu KC, Chu A, Go VLW, Saad MF: Hypovitaminosis D is associated with insulin resistance and $\beta$ cell dysfunction. Am J Clin Nutr. 2004, 79:820-825. 10.1093/ajcn/79.5.820

4. Pittas AG, Lau J, Hu FB, Dawson-Hughes B: The role of vitamin D and calcium in type 2 diabetes. A systematic review and meta-analysis. J Clin Endocrinol Metab. 2007, 92:2017-2029. 10.1210/jc.2007-0298

5. Mari A, Pacini G, Brazzale AR, Ahrén B: Comparative evaluation of simple insulin sensitivity methods based on the oral glucose tolerance test. Diabetologia. 2005, 48:748-751. 10.1007/s00125-005-1683-9

6. Wu CZ, Pei D, Su CC, et al.: Comparison of oral glucose insulin sensitivity with other insulin sensitivity surrogates from oral glucose tolerance tests in Chinese. Ann Acad Med Singap. 2010, 39:4-8.

7. Nagpal J, Pande JN, Bhartia A: A double-blind, randomized, placebo-controlled trial of the short-term effect of vitamin D3 supplementation on insulin sensitivity in apparently healthy, middle-aged, centrally obese men. Diabet Med. 2009, 26:19-27. 10.1111/j.1464-5491.2008.02636.x

8. American Diabetes Association: Standards of medical care in diabetes-2012. Diabetes Care. 2012, 35:11-63. 10.2337/dc12-s011

9. Holick MF: Vitamin D status: measurement, interpretation, and clinical application. Ann Epidemiol. 2009, 19:73-78. 10.1016/j.annepidem.2007.12.001

10. American Diabetes Association: Standards of medical care in diabetes-2010. Diabetes Care. 2010, 33:11. 10.2337/dc10-S011

11. Chatterjee R, Narayan KM, Lipscomb J, Jackson SL, Long Q, Zhu M, Phillips LS: Screening for diabetes and prediabetes should be cost-saving in patients at high risk. Diabetes Care. 2013, 36:1981-1987. 10.2337/dc121752

12. Trinder P: Determination of blood glucose using an oxidase-peroxidase system with a non-carcinogenic chromogen. J Clin Pathol. 1969, 22:158-161. 10.1136/jcp.22.2.158

13. Mari A, Pacini G, Murphy E, Ludvik B, Nolan JJ: A model-based method for assessing insulin sensitivity from the oral glucose tolerance test. Diabetes Care. 2014, 2063:539-548. 10.2337/diacare.24.3.539

14. Katz A, Nambi SS, Mather K, Baron AD, Follmann DA, Sullivan G, Quon MJ: Quantitative insulin sensitivity check index: a simple, accurate method for assessing insulin sensitivity in humans. J Clin Endocrinol Metab. 2000, 85:2402-2410. 10.1210/jcem.85.7.6661

15. Chen H, Sullivan G, Quon MJ: Assessing the predictive accuracy of QUICKI as a surrogate index for insulin sensitivity using a calibration model. Diabetes. 2005, 54:1914-1925. 10.2337/diabetes.54.7.1914

16. Matthews DR, Hosker JP, Rudenski AS, Naylor BA, Treacher DF, Turner RC: Homeostasis model assessment: insulin resistance and beta-cell function from fasting plasma glucose and insulin concentrations in man. Diabetologia. 1985, 28:412-419. 10.1007/BF00280883

17. Singh V, Misra AK, Singh M, et al.: An open-label, randomized, 10 weeks prospective study on the efficacy of vitamin D (daily low dose and weekly high dose) in vitamin D deficient patients. J Family Med Prim Care. 2019, 8:1958-1963. 10.4103/jfmpc.jfmpc_272_19

18. Kanauchi M, Kanauchi K, Inoue T, Kimura K, Saito Y: Surrogate markers of insulin resistance in assessing individuals with new categories "prehypertension" and "prediabetes". Clin Chem Lab Med. 2007, 45:35-39. 10.1515/CCLM.2007.015

19. Maestro B, Dávila N, Carranza MC, Calle C: Identification of a Vitamin D response element in the human insulin receptor gene promoter. J Steroid Biochem Mol Biol. 2003, 84:223-230. 10.1016/s09600760(03)00032-3

20. Maestro B, Molero S, Bajo S, Dávila N, Calle C: Transcriptional activation of the human insulin receptor gene by 1,25-dihydroxyvitamin D(3). Cell Biochem Funct. 2002, 20:227-232. 10.1002/cbf.951

21. Chen S, Villalta SA, Agrawal DK: FOXO1 mediates vitamin d deficiency-induced insulin resistance in skeletal muscle. J Bone Miner Res. 2016, 31:585-595. 10.1002/jbmr.2729

22. Gröber U, Holick MF: Diabetes prevention: vitamin D supplementation may not provide any protection if there is no evidence of deficiency!. Nutrients. 2019, 11:2651. 10.3390/nu11112651

23. He S, Yu S, Zhou Z, Wang C, Wu Y, Li W: Effect of vitamin D supplementation on fasting plasma glucose, insulin resistance and prevention of type 2 diabetes mellitus in non-diabetics: a systematic review and meta-analysis. Biomed Rep. 2018, 8:475-484. 10.3892/br.2018.1074

24. Barengolts E, Manickam B, Eisenberg Y, Akbar A, Kukreja S, Ciubotaru I: Effect of high-dose vitamin d repletion on glycemic control in African American males with prediabetes and hypovitaminosis D. Endocr Pract. 2015, 21:604-612. 10.4158/EP14548.OR

25. Heaney RP, French CB, Nguyen S, Ferreira M, Baggerly LL, Brunel L, Veugelers P.: A novel approach localizes the association of vitamin D status with insulin resistance to one region of the 25-hydroxyvitamin D continuum. Adv Nutr. 2013, 4:303-310. 10.3945/an.113.003731

26. Dutta D, Mondal SA, Choudhuri S, et al.: Vitamin-D supplementation in prediabetes reduced progression to type 2 diabetes and was associated with decreased insulin resistance and systemic inflammation: an open label randomized prospective study from Eastern India. Diabetes Res Clin Pract. 2014, 103:18-23. 10.1016/j.diabres.2013.12.044

27. Kuchay MS, Laway BA, Bashir MI, Wani AI, Misgar RA, Shah ZA: Effect of vitamin D supplementation on glycemic parameters and progression of prediabetes to diabetes: A 1-year, open-label randomized study. Indian J Endocr Metab. 2015, 19:387-392. 10.4103/2230-8210.152783

28. Nazarian S, St Peter JV, Boston RC, Jones SA, Mariash CN: Vitamin D3 supplementation improves insulin sensitivity in subjects with impaired fasting glucose. Transl Res. 2011, 158:276-281. 10.1016/j.trsl.2011.05.002

29. von Hurst PR, Stonehouse W, Coad J: Vitamin D supplementation reduces insulin resistance in South Asian women living in New Zealand who are insulin resistant and vitamin D deficient - a randomised, placebocontrolled trial. Br J Nutr. 2010, 103:549-555. 10.1017/S0007114509992017

30. Davidson MB, Duran P, Lee ML, Friedman TC: High-dose vitamin D supplementation in people with prediabetes and hypovitaminosis D. Diabetes Care. 2013, 36:260-266. 10.2337/dc12-1204 